05

\title{
Прочностные свойства полученной с применением аддитивной технологии керамики на основе оксида алюминия при ударно-волновом нагружении
}

\author{
(C) В.В. Промахов ${ }^{1}$, А.С. Савиных ${ }^{1,2}$, Я.А. Дубкова ${ }^{1}$, Н.А. Шульц ${ }^{1}$, \\ Н.В. Грунт ${ }^{1}$, С.В. Разоренов ${ }^{1,2}$ \\ ${ }^{1}$ Национальный исследовательский Томский государственный \\ университет, Томск, Россия \\ ${ }^{2}$ Институт проблем химической фризики РАН, Черноголовка, Московская \\ обл., Россия \\ E-mail: vvpromakhov@mail.ru
}

Поступило в Редакцию 18 мая 2018 г.

С помощью аддитивной технологии с последующим спеканием получены керамические образцы на основе оксида алюминия. Путем анализа полных волновых профилей образцов, зарегистрированных с помощью лазерного интерферометра в процессе их ударного сжатия амплитудой 6.8 и $13.8 \mathrm{GPa}$, определены динамический предел упругости и откольная прочность керамики.

DOI: 10.21883/PJTF.2018.19.46688.17393

В настоящее время для создания сложных инженерных изделий и конструкций широкое развитие получили аддитивные технологии. Основное отличие аддитивных технологий от традиционных методов получения изделий заключается в том, что модель (деталь или изделие) создается наращиванием тела изделия при точном объемном (3D) воспроизведении формы независимо от ее сложности. Широкое внедрение аддитивных технологий в производственный процесс может обеспечить революционный прорыв в промышленности, прежде всего потому, что аддитивные технологии позволяют с минимальными затратами реализовать любые конструкторские и инженерные идеи в наукоемких отраслях производства, таких как авиастроение, двигателестроение, ракетостроение, современные электронные приборы и др. 
Аддитивные технологии находятся на стадии понимания границ применимости материалов и изделий, полученных с их помощью. В связи с этим весьма актуальны вопросы о прочностных свойствах таких материалов при различных условиях внешних воздействий. Разработанные в Томском государственном университете технические решения позволяют создавать (печатать) изделия из технической керамики заданной геометрии. В настоящее время реализованы методы печати из оксидных керамических материалов, в частности из оксида алюминия. На их основе, например, появилась возможность создавать ячеистые сандвич-панели с сотовой структурой, предназначенные для теплозащиты и защиты от микрометеоритов современных космических устройств. Параметры таких панелей предполагают рабочие температуры до $2000^{\circ} \mathrm{C}$ в условиях воздействия высокоскоростными потоками плотностью не более $0.8 \mathrm{~g} / \mathrm{cm}^{3}$.

Для достижения высокой эффективности таких керамических материалов, применяемых в изделиях и конструкциях, подверженных высокоскоростной интенсивной деформации, необходима детальная информация об их прочностных свойствах в условиях динамического деформирования и разрушения. Она необходима также для построения адекватных моделей разрушения новых аддитивных материалов и конструкций, правильно описывающих весь спектр явлений, сопровождающих их динамическое разрушение. Построение адекватной модели невозможно без экспериментальных исследований процесса разрушения материалов в субмикросекундном диапазоне динамических воздействий. Такая информация может быть актуальна при решении задач защиты космических аппаратов от ударов микрометеоритов и экстремальных тепловых воздействий при прохождении ими, например, через пылевые облака в непосредственной близости от ядра кометы. Оценки показывают, что при этом можно ожидать столкновений с пылевыми частицами, имеющими массу $10^{-1}-10^{-3} \mathrm{~g}$ и скорость относительно аппарата $60-80 \mathrm{~km} / \mathrm{s}[1,2]$.

Задачей настоящей работы является исследование прочностных свойств при ударно-волновом нагружении керамики на основе оксида алюминия, полученной с применением аддитивной технологии.

Для 3D-печати керамических образцов использовалось устройство, описанное в работе [3], требуемая геометрия детали проектировалась в системе CAD (computer-aided design). Изготовление образцов необходимой формы из термопластичной суспензии (смеси керамических

7 Письма в ЖТФ, 2018, том 44, вып. 19 
порошков и термопластичного связующего) осуществлялось послойно методом наплавления. На рис. 1, $a$ представлена фотография процесса послойного наплавления термопластичной высоконаполненной суспензии из керамических порошков на основе оксида алюминия, на рис. $1, b$ - снимок полученного образца. После формования полуфабриката с целью удаления связующего заготовка отжигалась в воздушной печи при температуре $1100^{\circ} \mathrm{C}$, затем проводилось высокотемпературное спекание образцов при $1700^{\circ} \mathrm{C}$ в течение часа. Исследования структуры полученных образцов керамики проводились с использованием растрового электронного микроскопа PHILIPS SEM 515 и электронного микроскопа системы QUANTA 3D. Исследования структуры полученных образцов керамики на основе оксида алюминия показали, что после спекания в образцах присутствует остаточная пористость около 7-10\%. Средний размер зерен оксида алюминия составлял $\sim 7 \mu \mathrm{m}$ (рис. $2, a$ ). Установлено, что после спекания образцов контролируемая высота слоя составила около $400 \mu \mathrm{m}$. Особое значение имеет результат, свидетельствующий о том, что внутренняя структура керамики монолитна, не было зафиксировано различимых границ между слоями материала в образцах (рис. $2, b$ ).

Прочностные свойства керамики на основе оксида алюминия, полученной с применением аддитивных технологий, при динамическом нагружении изучались с использованием техники ударно-волнового эксперимента [4]. При измерениях использовался тот факт, что структура ударной волны и динамика волновых взаимодействий в исследуемом материале определяются помимо термодинамического уравнения состояния вещества процессами упругопластического деформирования и разрушения в материале. В работе регистрировались профили скорости свободной поверхности образцов в процессе ударного сжатия с последующим расчетом динамического предела упругости (HEL) и критических растягивающих напряжений (откольной прочности).

Исследуемые образцы керамики оксида алюминия представляли собой шлифованные с обеих сторон диски диаметром $35 \mathrm{~mm}$ с номинальной толщиной $5 \mathrm{~mm}$. Измеренная гидростатическим методом плотность составила $3.5 \mathrm{~g} / \mathrm{cm}^{3}$, среднее значение продольной скорости звука $-8.6 \pm 0.15 \mathrm{~km} / \mathrm{s}$. Плоские волны сжатия в исследуемых образцах генерировались ударом алюминиевой пластины-ударника толщиной $2 \mathrm{~mm}$, разогнанной до скорости $0.66 \pm 0.03$ и $1.8 \pm 0.05 \mathrm{~km} / \mathrm{s}$ с использованием взрывных устройств [4]. Образцы размещались на

Письма в ЖТФ, 2018, том 44, вып. 19 

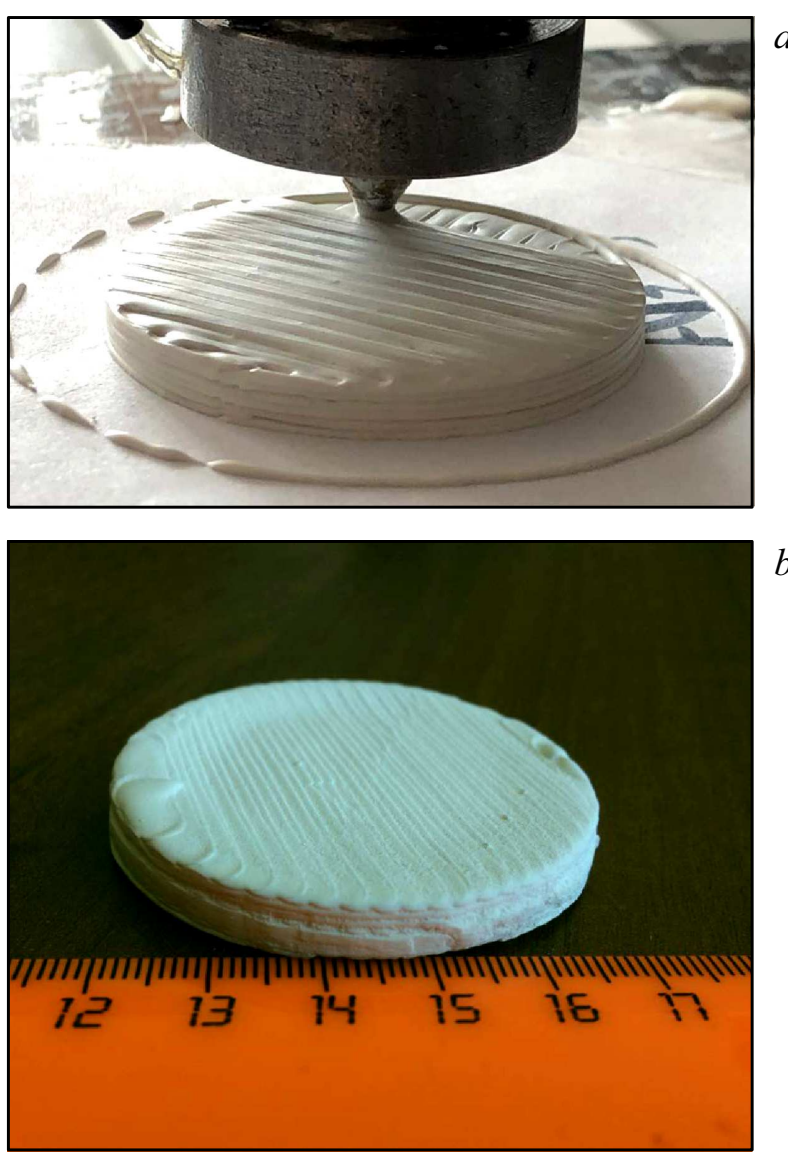

Рис. 1. $a-$ изображение процесса 3D-печати образцов из керамики на основе оксида алюминия, $b-$ фотография полученного образца.

алюминиевых экранах толщиной $2 \mathrm{~mm}$. Во всех экспериментах с помощью лазерного допплеровского измерителя скорости VISAR [5] регистрировались профили скорости свободной поверхности $u_{f s}(t)$. Для отражения лазерного излучения на поверхность образца путем вакуумного напыления наносилось отражающее покрытие из алюминия толщиной несколько микрометров.

7* Письма в ЖТФ, 2018, том 44, вып. 19 

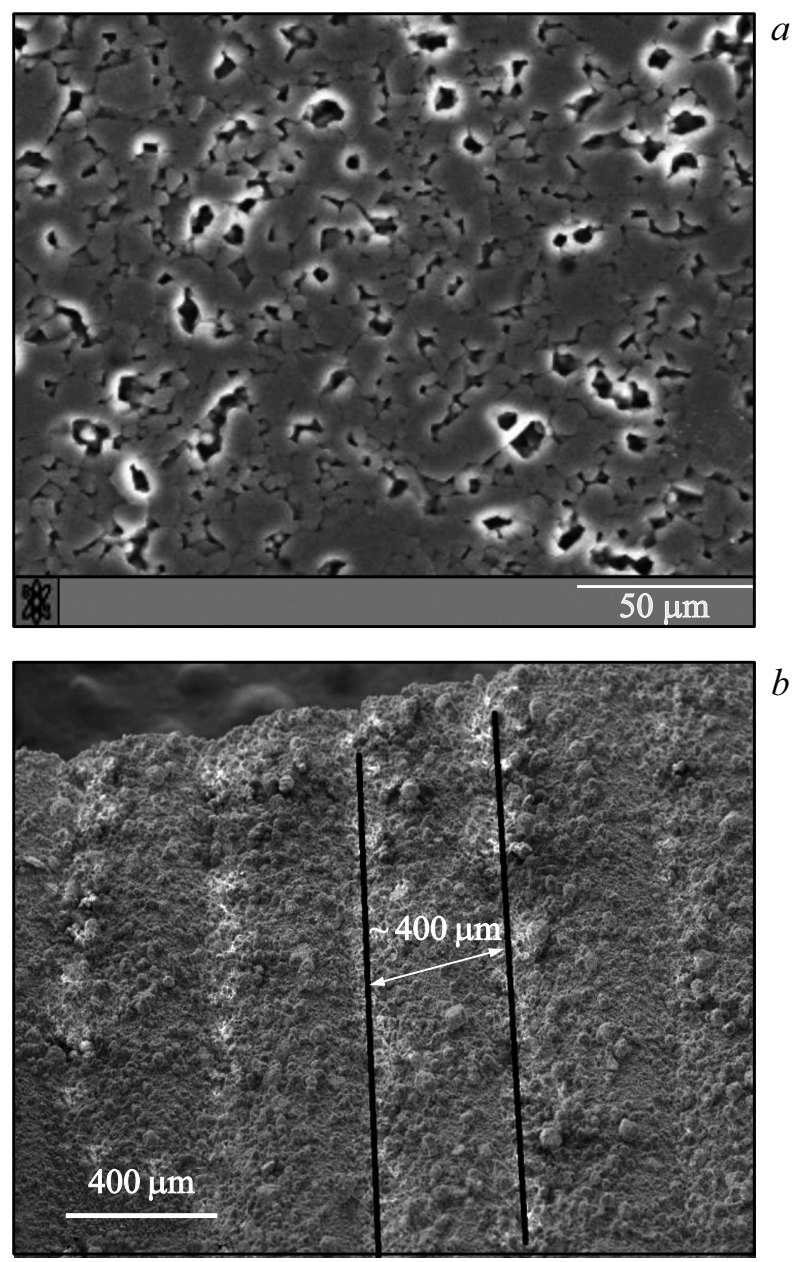

Рис. 2. Структура керамики (снимки получены с применением растровой электронной микроскопии). $a$ - зеренная структура материалов, $b-$ торцевая поверхность образцов (линиями обозначены границы одного печатного слоя).

На рис. 3, $a$ представлены профили свободной поверхности исследуемых образцов керамики оксида алюминия. В обоих случаях фиксируется

Письма в ЖТФ, 2018, том 44, вып. 19 

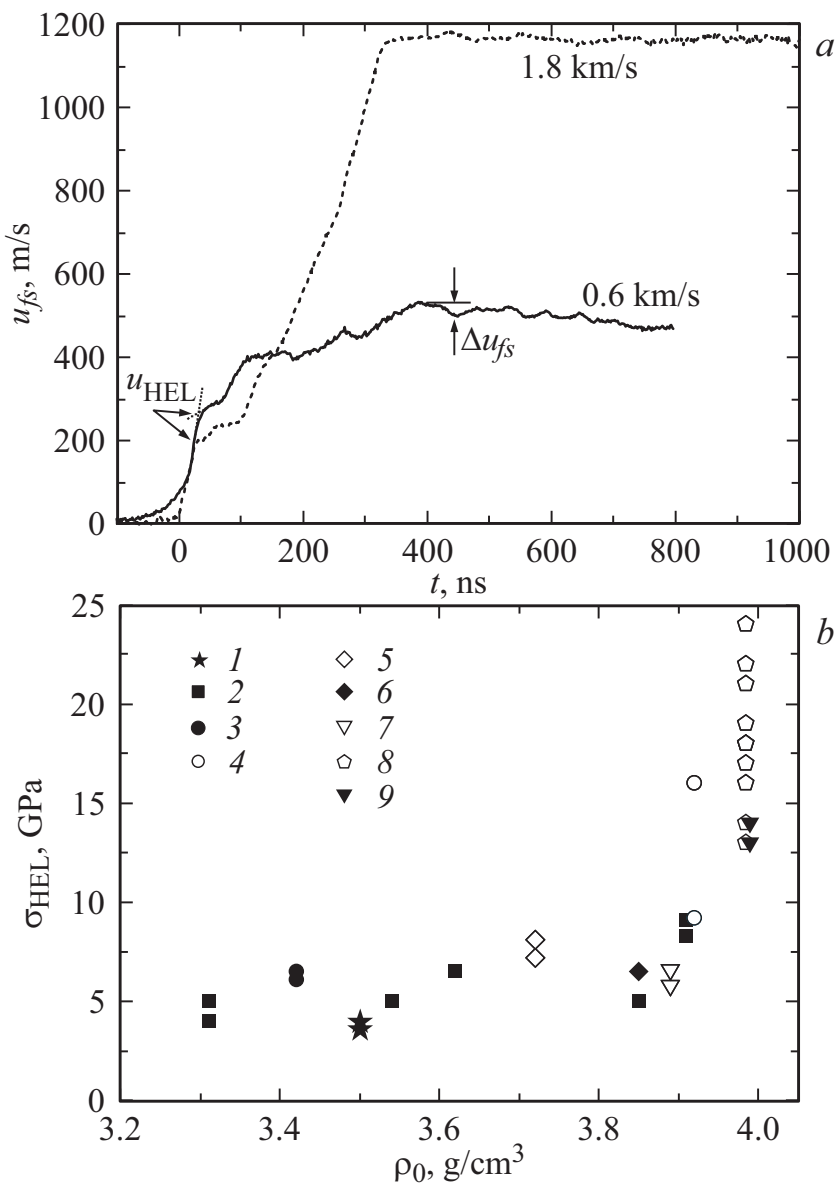

Рис. 3. Результаты ударно-волнового нагружения керамических образцов, полученных с применением аддитивной технологии. $a-$ профили скорости свободной поверхности (указаны скорости ударников). $b-$ динамический предел упругости керамики оксида алюминия в сопоставлении с литературными данными. 1 - данные настоящей работы, 2 - ENSCI [6] (размер зерна слева направо: 0.6, 1, 11, 5-125, $4.7 \mu \mathrm{m}), 3$ - AD-85 [7], 4 - горячепрессованный Carborundum Co. [7], 5 - Diamonite P-3142-1 [7], 6 - спеченный В6 [8], 7 - AD-995 [9], 8 - монокристаллический сапфир различных ориентаций [10], 9 - D999 [11].

Письма в ЖТФ, 2018, том 44, вып. 19 
выход на поверхность упругой и пластической волн сжатия. В пластической волне рост скорости происходит ступенчато. Такая структура пластической волны связана с неоднородностью объемной структуры, наличием пор и других дефектов. Четкий переход от упругого к пластическому сжатию не регистрируется, поэтому величина динамического предела упругости $\sigma_{\mathrm{HEL}}$ определялась экстраполяцией скорости поверхности за фронтом предвестника к нулевому моменту времени, как это показано на рис. 3, $a$ пунктирными линиями. По найденному таким способом значению $u_{\mathrm{HEL}}$ величина $\sigma_{\mathrm{HEL}}$ рассчитывается как $\sigma_{\mathrm{HEL}}=\rho_{0} c_{l} u_{\mathrm{HEL}} / 2$, где $\rho_{0}-$ плотность, $c_{l}-$ продольная скорость звука. Результаты измерений динамического предела упругости суммированы на рис. $3, b$, где они сопоставлены с имеющимися данными для других керамик на основе окиси алюминия. Видно, что полученные значения $\sigma_{\mathrm{HEL}}$ для исследованной керамики лежат в нижней части массива точек, взятых из литературы.

На профилях скорости свободной поверхности фиксируется только начальная часть волны разрежения, распространяющейся вслед за волной сжатия, ограниченная величиной откольной прочности $\sigma_{s p}$. Ее значение для исследуемой керамики оценивалось по измеренной величине $\Delta u_{f s}$ как $\sigma_{s p}=\rho_{0} c_{l} \Delta u_{f s} / 2$ [4]. Найденные значения $\sigma_{s p}$ при скорости удара $1.8 \mathrm{~km} / \mathrm{s}$, что соответствует максимальному напряжению ударного сжатия $13.8 \mathrm{GPa}$, составили $0.38 \mathrm{GPa}$, при скорости удара $0.6 \mathrm{~km} / \mathrm{s}$ $(6.8 \mathrm{GPa})-0.44 \mathrm{GPa}$. Максимальные напряжения ударного сжатия превышают значения $\sigma_{\mathrm{HEL}}$ в 3.8 и 1.8 раза соответственно. Следует отметить, что при превышении динамического предела упругости значения $\sigma_{s p}$ исследованной керамики значительно больше нуля. Например, в работе [11] проведены измерения $\sigma_{s p}$ керамики $\mathrm{AD}-85$ и показано, что при максимальных напряжениях сжатия, равных $\sigma_{\mathrm{HEL}}$, значение откольной прочности принимает нулевое значение. Для керамики AD-995, исследовавшейся в работе [12], нулевые значения откольной прочности регистрируются при максимальных напряжениях сжатия, превышающих $\sigma_{\mathrm{HEL}}$ более чем в $1.5-1.7$ раза. Значения откольной прочности керамик при максимальном ударном сжатии выше $\sigma_{\mathrm{HEL}}$, измеренные в работах $[11,12]$, лежат в диапазоне от 0.3 до $0.6 \mathrm{GPa}$. Вероятно, с началом пластической деформации вблизи предела упругости происходит растрескивание по границам зерен, в то время как уплотнение пористой керамики при высоких давлениях ударного сжатия сопровождается усилением межзеренных связей. В связи с этим,

Письма в ЖТФ, 2018, том 44, вып. 19 
можно отметить, что установление прочных связей между частицами пористого материала непосредственно в процессе его уплотнения в ударной волне ранее наблюдалось в экспериментах с порошкообразным алюминием [13].

Регистрация профилей скорости свободной поверхности образцов керамик $\mathrm{Al}_{2} \mathrm{O}_{3}$, полученных с применением аддитивных технологий, в процессе ударного сжатия позволила определить динамический предел упругости $\left(\sigma_{\mathrm{HEL}}\right)$ и откольную прочность материала $\left(\sigma_{s p}\right)$. Значение $\sigma_{\mathrm{HEL}}$ для исследованной керамики коррелирует с данными для керамик близкой плотности и составляет от 3.5 до $4 \mathrm{GPa}$. Измерение величины $\sigma_{s p}$ проводилось в диапазоне максимальных напряжений сжатия, превышающих $\sigma_{\text {HEL }}$ в 3.8 и в 1.8 раза. Полученные значения откольной прочности равны 0.38 и $0.44 \mathrm{GPa}$ соответственно и слабо зависят от максимального напряжения сжатия.

Часть исследований по разработке научно-технических подходов 3D-печати керамики выполнена при поддержке Программы повышения конкурентоспособности ТГУ, исследования по получению образцов и их ударно-волновому нагружению выполнены в рамках гранта РФФИ № 17-38-50126 мол_нр с использованием оборудования Московского регионального взрывного центра коллективного пользования РАН.

\section{Список литературы}

[1] Reinhardt R. // ESA Bull. 1982. N 29. P. 68-83.

[2] Агурейкин В.А., Анисимов С.И., Бушман А.В., Канель Г.И., Карягин В.П., Константинов А.Б., Крюков Б.П., Минин В.Ф., Разоренов С.В., Сагдеев Р.3., Сугак С.Г., Фортов В.Е. // ТВТ. 1984. Т. 22. № 5. С. 964-983.

[3] Промахов В.В., Жуков И.А., Ворожцов С.А., Шевченко М.В., Платов В.А., Архипов В.А., Муравлев Е.В. // Ползуновский вестник. 2016. Т. 1. № 4. C. $59-63$.

[4] Канель Г.И., Разоренов С.В., Уткин А.В., Фортов В.Е. Ударно-волновые явления в конденсированных средах. М.: Янус-К, 1996. 408 с.

[5] Asay J.R., Barker L.M. // J. Appl. Phys. 1974. V. 45. N 6. P. 2540-2546.

[6] Longy F., Cagnoux J. // J. Am. Ceram. Soc. 1989. V. 72. N 6. P. 971-979.

[7] Gust W.H., Royce E.B. // J. Appl. Phys. 1971. V. 42. N 1. P. 276-295.

[8] Savinykh A.S., Kanel G.I., Razorenov S.V., Rajendran A. // AIP Conf. Proc. 2006. V. 845. N 1. P. $888-891$.

Письма в ЖТФ, 2018, том 44, вып. 19 
[9] Grady D.E. // High-pressure science and technology. N.Y.: American Institute of Physics, 1994. P. 741-744.

[10] Kanel G.I., Nellis W.J., Savinykh A.S., Razorenov S.V., Rajendran A.M. // J. Appl. Phys. 2009. V. 106. N 4. P. 043524.

[11] Murray N.H., Bourne N.K. Rosenberg Z. // Shock compression of condensed matter. N.Y.: American Institute of Physics, 1996. P. 491-494.

[12] Dandekar D.P., Bartkowski P. // High-pressure science and technology. N.Y.: American Institute of Physics, 1994. P. 733-736.

[13] Дремин А.Н., Канель Г.И., Молодеи, А.М. // Физика горения и взрыва. 1972. T. 8. № 2. C. 283-290. 